\title{
The Composition of Soy-Bean Oil ${ }^{1}$
}

By W. B. Smith"

Armour \& Co., Kansas Crty, Kansas

$\mathbf{V}^{\mathrm{H}}$ ERY little seems to have been published regarding the composition of soy-bean oil, although many data concerning its "constants" have appeared in the last few years. Matthes and Dahle's ${ }^{3}$ statement that the fatty acids consist of 15 per cent palmitic, 56 per cent oleic, 19 per cent linolic, and 5 per cent linolenic acids, has been quoted recently, but as the iodine number of such a mixture is 99 , while soy-bean oil has an iodine number around 130 , it is evident that this is not the correct composition.

The principal reason for the discrepancy lies in the fact pointed out by Jamieson and Baughman, ${ }^{4}$ that a large proportion of the linolic tetrabromides of some oils remains in solution in the mixture of oleic dibromide and petroleum ether. When this fact is recognized, the correlation of the analysis of the unsaturated acids with the known constants becomes simplified. Some of the chief constants which have been published are the following:

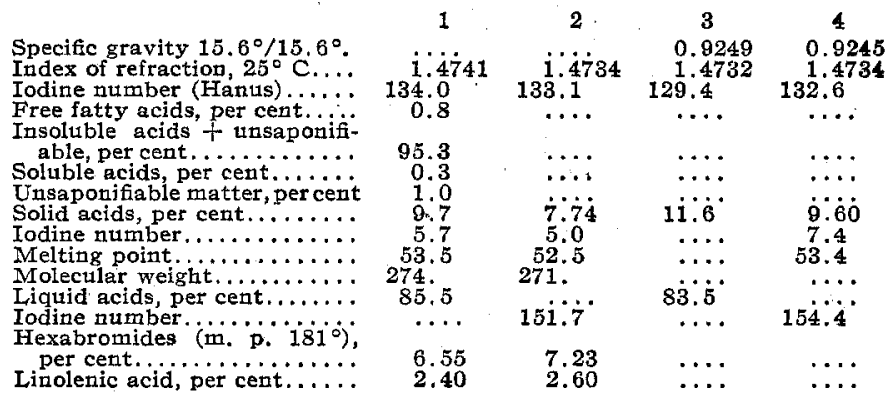

acids when corrected for this becomes 9.3. This result is very close to that of Fellers. ${ }^{5}$ Owing to the small quantities of solid acids recovered, tests of their character were inconclusive. According to Matthes and Dahle, ${ }^{3}$ palmitic acid is the only saturated acid present.

The percentage of linolenic acid in soy-bean oil appears to

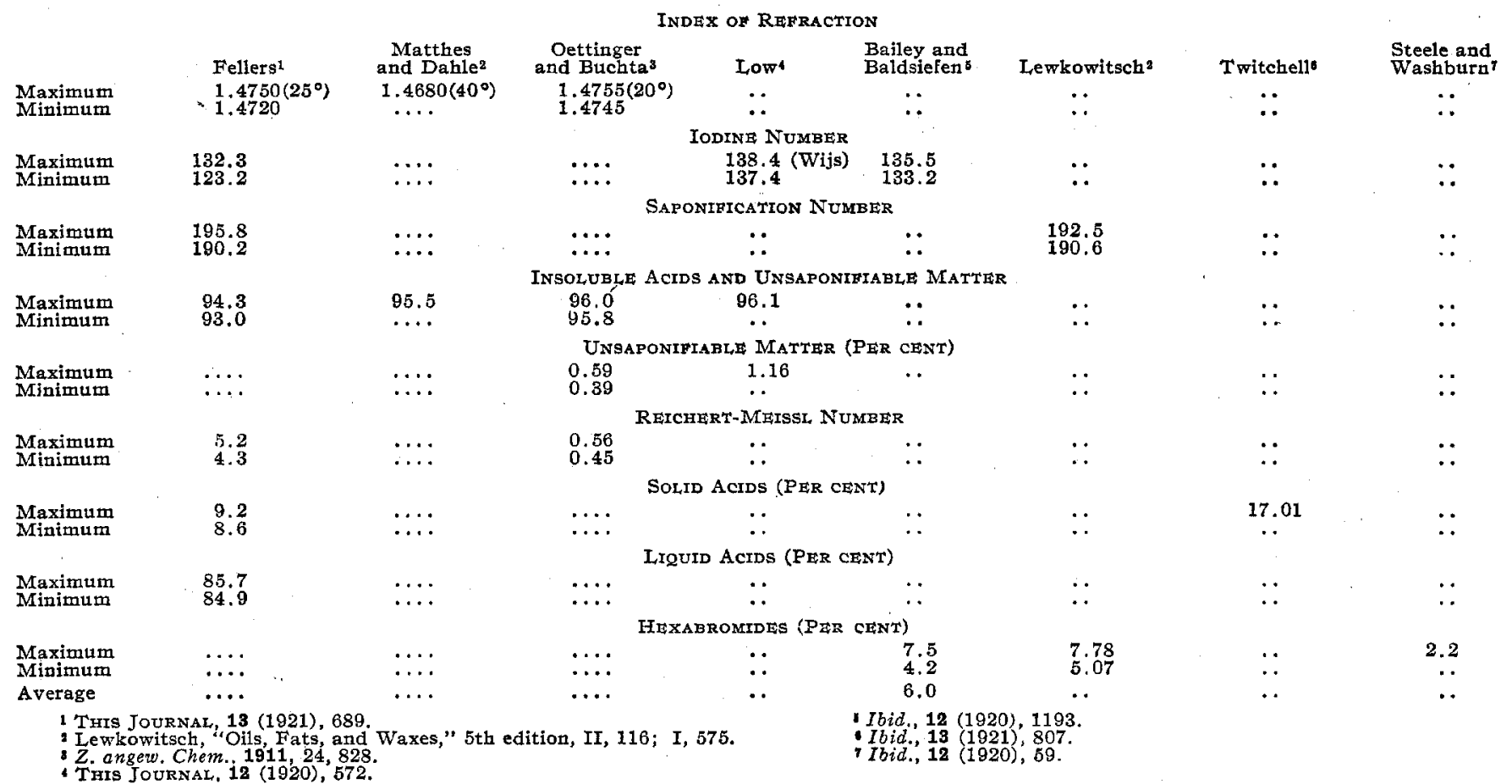

\section{EXPERTMENTAL}

Analyses bearing on the subject have been made on four samples of soy-bean oil, representing four different sources as well as more than ten years' time. Standard methods were employed in every case, more than ordinary care being observed.

These analyses average 9.7 per cent of solid acids, with an average iodine number of 6 , Taking the iodine value of the unsaturated acids as 153 , the solid acids contain about 4 per cent of unsaturated acids, so that the percentage of saturated

1 Received January 13, 1922.

2 Chemist, Armour \& Co.

I Iewkowitsch, "Oils, Fats, and Waxes," 5th edition, II, 116; I, 575.

'J. Am. Chem. Soc., 42 (1920), 1199. have been well worked out. Excluding Steele and Washburn's result, ${ }^{6}$ which is much lower than the others, the limits are from 4.2 to 7.8 per cent of hexabromide, corresponding to 1.54 to 2.86 per cent of linolenic acid. . Bailey and Baldsiefen found the average of hexabromides to be 6.0 , equivalent to 2.2 per cent of linolenic acid. The average of 2.5 per cent found experimentally agrees with these figures.

The palmitic and linolenic acids account for less than 12 per cent of the oil, which must contain a large proportion of linolic acid. To determine this, Oil 1 was tested in the manner described by Jamieson and Baughman." The filtrate from the hexabromide determination was freed from ether

- This Journat, 13 (1921), 689.

- Ibid., 12 (1920), 59. 